Institute of $\mathbf{F}_{\text {ood and }} \mathbf{A g r i c u l t u r a l}_{\mathbf{S}} \mathbf{S}_{\text {ciences }}$

\title{
Say Goodbye to Mildew and Save Energy Home Study Course - Part II: Moisture the Culprit - How It Gets Into Your Home ${ }^{1}$
}

Virginia Peart ${ }^{2}$

Moisture problems, such as mildew and corrosion, cost residents of Florida and other southeastern coastal regions millions of dollars. You may have heard horror stories about mildew: mildew throughout a home on walls, fabrics, and furnishings; costly clean-up and repainting jobs that don't last because mildew comes back again and again; people who are allergic to mildew, but can't rid their homes of musty smells.

Running air conditioning continually to eliminate mildew problems, without controlling moisture, requires a lot of electric energy. As power production costs continue to rise, electrical utility bills rise. To save energy, to save money, to avoid the work of mildew clean-up and potential mildew allergy problems, people want to prevent mildew problems. If they already have mildew problems, they would like to stop them and keep mildew from spreading. Prevention of mildew in warm, humid climates requires an understanding of both mildew, what makes it grow and spread, and what can be done to control the situation.

\section{Part II}

There are many types of mildew, but what makes mildew grow is pretty much the same for every type. The conditions that promote or stop mildew growth are the same in all parts of the country or anywhere in Florida. Part I of this home study course provided help for understanding what mildew is and what makes it grow. Part II was designed to help you understand why humidity is often high in Florida homes.

\section{Indoor Sources of Moisture}

Where does moisture in a home come from?

Some moisture comes from activities of the family in the home. Breathing alone contributes

1. This document is FCS 3212, one of a series of the Department of Family, Youth and Community Sciences, Florida Cooperative Extension Service, Institute of Food and Agricultural Sciences, University of Florida. Publication date: September 2002. First published in December 1990 by the Florida Energy Extension Service. Reviewed: September 2002 Please visit the EDIS Web site at http://edis.ifas.ufl.edu

2. Written by Virginia Peart, former Associate Professor, Housing, Department of Family, Youth and Community Sciences, Cooperative Extension Service, Institute of Food and Agricultural Sciences, University of Florida, Gainesville, 32611 and reviewed by Nayda I. Torres, Professor, Family and Consumer Economics, Department of Family, Youth and Community Sciences, Cooperative Extension Service, Institute of Food and Agricultural Sciences, University of Florida and Dale Dorman, Extension Housing and Environment Specialist - Emeritus, Cooperative Extension Service, University of Georgia. 
about 3 pints of water into the air per day per person. Cooking -- especially without covers on pans -- not only adds moisture to air, but also takes more energy. Bathing and cleaning also add moisture. All the water you put on your plants ends up in the air. Even burning gas or oil in ranges and heaters produces water vapor. Reducing the moisture produced inside your home can help prevent mildew problems.

Please don't stop bathing! But recognize the contribution bathing makes to moisture and mildew problems. Bathing and showering can put more moisture in the air than the air in the bathroom can hold. Moisture can condense on the mirror and walls and can be carried into other parts of the house. The half-pint of moisture in the air from a shower isn't all of the moisture left after bathing. Water droplets clinging to a shower or tub, and water left in towels will evaporate as the moisture in the air spreads to other parts of the house. This might add another pint or two to the total indoor air moisture. A bathroom exhaust fan properly used can help.

People turn off the lights and fall asleep at night, but they keep breathing -- breathing produces moisture. Two people over an 8-hour period can produce one and a half pints more moisture than a bedroom can hold. Mildew often occurs in bedrooms.

Should ventilation be used to remove moisture produced inside our home?

Q: When to open windows and doors to reduce moisture and mildew problems?

A: When outside air is dry enough.

\section{How Can You Know?}

Conventional wisdom may suggest that we should open windows to get rid of excess moisture before it can cause trouble. Ventilation works well in parts of the country where outside air is drier. In Florida and other southern coastal regions there is a question. It is important to know when outside air is dry enough to use ventilation to prevent mildew and other moisture problems.

\section{Dew Point Temperature Below 55 $\mathrm{F}$}

The answer to the question, "Can ventilation be used to remove moisture build-up in a home?" is Yes -- when the outside air is dry enough. We can know it is dry enough when the dew point temperature (or nighttime low) is $55^{\circ} \mathrm{F}$ or lower. This information is available through weather reports. When the dew point temperature (or nighttime low) is 65,70 , or $75^{\circ} \mathrm{F}$, it is especially important to keep air with this high moisture from coming into your house.

What is the dew point temperature, anyway?

The dew point temperature is an indicator of the actual amount of moisture in air. The dew point temperature is the temperature at which moisture in the air begins to condense.

When we find dew on grass in the morning, we know that the temperature of grass reached the dew point sometime during the night before. As air cools during the night, it can hold less and less moisture and the relative humidity will get very high. Finally, air becomes so cool and saturated, it releases some moisture as dew. The local dew point temperature is sometimes given on television weather reports. When the dew point temperature is not provided, the nighttime low temperature is a good estimate of the dew point temperature and the amount of moisture held in the air.

\section{Humid Air Infiltration Sites}

Some outside air comes into a home when people come and go. We all know enough not to leave doors to the outside open when weather is very humid, but keeping doors to the outside 
closed when not in use won't keep all outside moisture from coming in. Even a tightly built, weather-stripped house can have $1 / 2$ to one air change per hour. That is, new air can come in through tiny cracks and crevices around windows and doors, through utility outlets and the fire place. Exhaust fans in bathrooms and the kitchen can step up the air change process. Older homes sometimes have as many as 2 air changes each hour. If the outside air is cool, it will be drier than inside air. On the other hand, during warm, humid weather, each air change can bring in 3 to 6 pints of moisture. During a day, 9 to 18 gallons of moisture can be brought into a home through infiltration. This excess moisture contributes to mildew problems and requires energy to remove.

\section{Cooling and Dehumidification BTU Days}

The chart in Figure 1 shows how weather in Florida changes over a 12-month period and how much moisture air conditioning must remove from air that gets into a house. The cooling line is based on the air conditioning and heating that would be required for each month. The dehumidification line indicates the air conditioning dehumidification needed to produce mildew safe humidity levels. You can see that little cooling is needed until about May. The humidity during this time is lower, too. As the need for cooling increases during the summer

COOLING AND DEHUMIDIFICATION BTU DAYS ORLANDO, FLORIDA

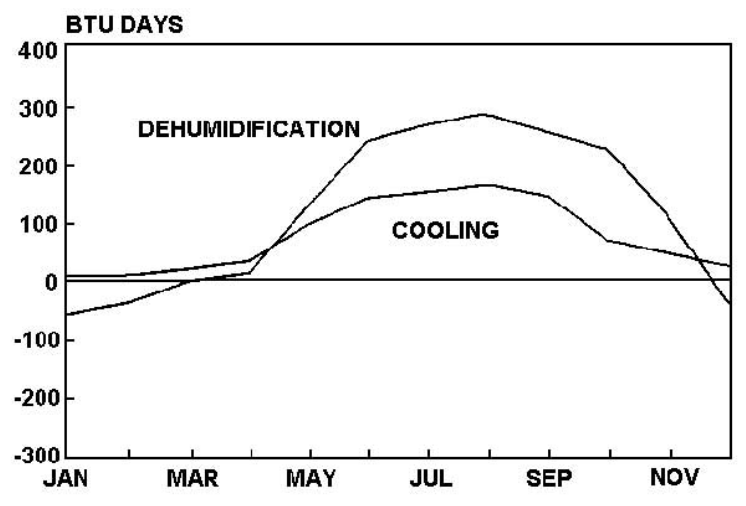

months, the need for dehumidification increases as well. As cooling requirements of infiltrated air drop off in the fall, the dehumidification needs are still high.

Figure 1 shows that most of the year in Florida, air that comes in through cracks and crevices and from holding doors open lets in much more moisture than heat. And moisture is harder to remove than heat.

By comparison, the charts in Figure 2 compare the cooling and dehumidification needs for Atlanta, Georgia and Boston, Massachusetts. You can see the climate is much drier in these parts of the country. Ventilation will bring in drier air most of the time.

\section{COOLING AND DEHUMIDIFICATION BTU DAYS}
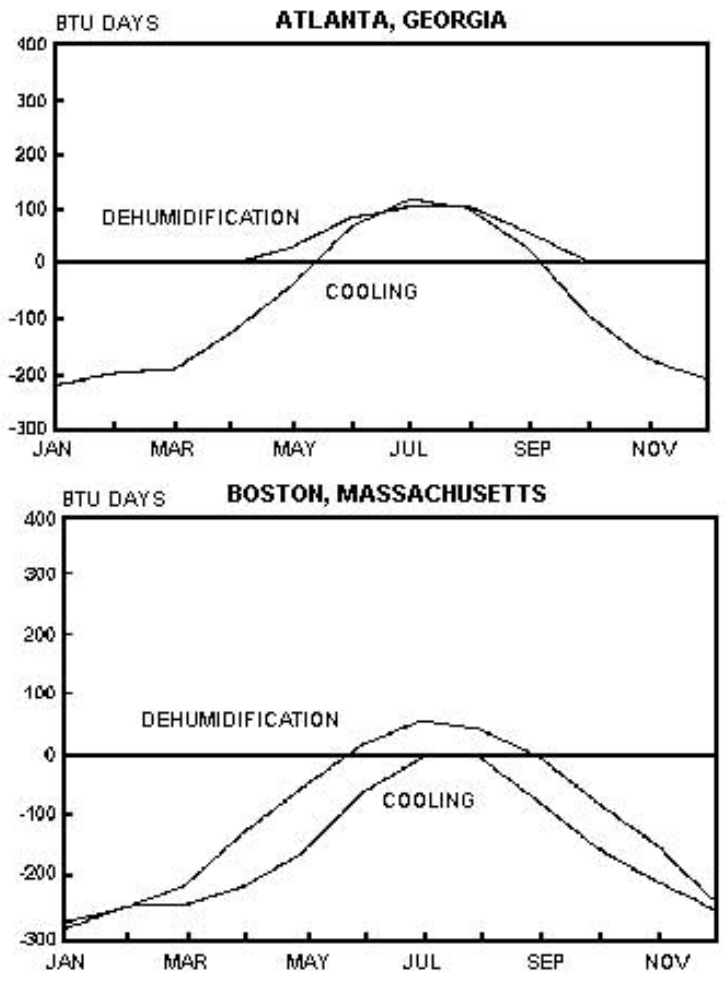


\section{Stop Unwanted Humid Air Infiltration}

Air conditioners remove moisture from air as the air is cooled. In drier parts of the country moisture removal by air conditioning is usually sufficient. However, air conditioners are designed to cool more than they dehumidify air. This can cause a problem in the warm, humid climates of Florida and southern coastal areas. In Figure 1, summer dehumidification needs are much greater than the need for cooling air only. This means, in warm, humid climates it is important to stop unwanted infiltration of air and limit air change by ventilation. By repeatedly returning air to the air conditioner, enough moisture can be "wrung out" of air to help keep indoor humidity levels below the MILDEW ALERT level. Drier air takes less energy to cool so energy is saved, too.

Even during drier parts of the year (December through April) there can be humid days or even weeks. As Table 1 shows, every month has some days with high humidity levels. Air conditioning and dehumidification may be needed almost anytime of the year in Florida.

\section{Home Furnishings Hold Moisture Relative Humidity Makes the Difference}

The higher the relative humidity, the more moisture materials in a home will absorb. The temperature, warm or cool, doesn't make a difference in the amount of moisture materials will hold. Relative humidity does make a difference. Did you ever leave a towel or jacket outside overnight? Remember, how damp it had become?

When air conditioning can't keep up with the dehumidification, the relative humidity inside a home can get quite high. There is a serious problem when the humidity in a home is
Table 1.

\begin{tabular}{|c|c|}
\hline \multicolumn{2}{|c|}{$\begin{array}{c}\text { HIGH HUMIDITY POTENTIAL } \\
\text { ORLANDO, FLORIDA }\end{array}$} \\
\hline Month & $\begin{array}{c}\text { High Dew Point } \\
\text { Temperature }\end{array}$ \\
\hline January & 60 * \\
\hline February & 65 * \\
\hline March & 64 * \\
\hline April & 62 * \\
\hline May & 70 * \\
\hline June & 74 * \\
\hline July & 78 * \\
\hline August & 76 * \\
\hline September & $75^{*}$ \\
\hline October & 74 * \\
\hline November & $75^{*}$ \\
\hline December & 69 * \\
\hline
\end{tabular}

consistently high: the house structure and furnishings soak moisture up like a sponge. Fabrics feel damp. Paper becomes limp.

Suppose a family decides to turn off their air conditioner and sleep with the windows open. The moisture absorbed by furnishings can be as much as 100 pounds or about 12 and a half gallons. When the windows are closed again in the morning and air conditioning is again turned on, that moisture will be given up slowly during the day. This excess moisture can make an air conditioner work harder the next day, or make the house clammy feeling and encourage mildew growth. On hot days $\left(90^{\circ}\right.$ or higher) windows and doors should be kept closed and air conditioning kept on both day and night, not to just cool air, but also to keep the relative humidity low. 


\title{
Test Your Knowledge
}

See the quiz to test your knowledge.

\author{
QUIZ \\ Moisture -- The Culprit
}

Circle Your Answer

True or False

$\mathrm{T} \quad \mathrm{F} \quad$ Breathing can put a lot of moisture in the air in a home.

$T \quad F \quad$ It is always a good idea to open windows and ventilate with fresh air when moisture builds up in a home.

T $\quad \mathrm{F} \quad$ Either the dew point temperature or the nighttime low temperature is a pretty good indicator of how humid outside air will be the next day.

T $\quad \mathrm{F} \quad$ Air that infiltrates into homes in Florida is much more humid, and requires much more dehumidification than air that infiltrates into homes in Atlanta, GA or Boston, MA.

T F Air conditioners for Florida may not dehumidify enough if too much outside air comes into a home through infiltration.

T $\quad \mathrm{F}$ When humidity builds up in homes, the furnishings soak up water and make air conditioning work harder and make the house feel clammy.

\section{Part III}

Provides you with techniques to reduce moisture in mildew hot spots in your home. 